\title{
Verbal Paired Associates I Subtest (WMS-
} IV)

National Cancer Institute

\section{Source}

National Cancer Institute. Verbal Paired Associates I Subtest (WMS-IV). NCI Thesaurus. Code C120344.

A subtest of the Wechsler Memory Scale, 4th Edition that evaluates verbal memory for associated word pairs. After 10 or 14 word pairs are read to the subject, the first word of each pair is read, and the subject is asked to provide the corresponding word. 